suitable mechanical apparatus. The method given for the preparation of acetamide from ethylacetate has long been used in this College without breakage.

The reviewer's statement anent the osazone method of distinguishing sugars is " not strictly accurate" - a phrase familiar to his pen but not to his judgment. As well as giving the melting points of osazones of the sugars mentioned, we give (on p. 283) the theory and method for their preparation, and emphasise the use of the microscope in their identification. Surely that is sufficient in a book of organic preparations.

William M. Cumming.

I. VANCE HOPPER.

T. S. WHEELER.

Royal Technical College, Glasgow, and Research Department,

Royal Arsenal, Woolwich, April 17.

I AM content to let those competent to judge decide whether my strictures on Messrs. Cumming, Hopper, and Wheeler's book were justified, and I do not think it would serve any useful purpose to deal with the authors' reply in detail in the columns of NATURE. My own view is that the work has not been compiled with sufficient care to be suitable for undergraduates' use, and I tried to express this opinion in my review. Apart from cardinal errors, statements are made which are incorrect without considerable qualification; such may not deceive the experienced, but are particularly dangerous to the beginner. I quoted some of the errors together with a few typographical mistakes; these were sufficient to justify my contention, though others could be cited.

The Writer of the Review.

\section{Geology of Ireland.}

WHEN the writer of the obituary notice in NATURE of May 3 expressed regret that the late Prof. Grenville A. J. Cole was not spared to write a comprehersive work on the geology of Ireland, he seems to have overlooked the volume on the British Isles in the "Handbuch der Regionalen Geologie" Series, to which the late Prof. Cole contributed all the portions dealing with Ireland.

Before his death, Prof. Cole revised this matter with the assistance of Mr. Timothy Hallissy, of the Geological Survey of Ireland. This is now in the printers' hands, and will form a separate volume on the geology of Ireland which we shall publish shortly.

I Fleet Lane, Thos. Murby and Co.

Ludgate Circus, E.C.4.

\section{The Theory of Hearing.}

Prof. Scripture's letter in Nature of April 26 leaves me in great perplexity, for when I performed the experiment he suggested with a series of light pendulums of different length driven by resonance from a heavy pendulum of variable length, my findings did not at all tally with his description. According to Prof. Scripture, a variation in the rate of the driving pendulum should have been followed by irregular jangling of all the driven pendulums. But I did not observe this happening, if the change in length of the driving pendulum was carefully effected without interrupting its motion.

Suppose that the driving pendulum is set swinging and that a few minutes later the driven pendulums are examined. It will be seen that the swinging No. 2846 , VOL. I I 3$]$ motion affects a group of the latter. In the centre of the group is the "in tune " pendulum, on either side are the slightly out of tune pendulums which are undergoing forced vibrations. Suppose now that the length of the driving pendulum is gradually increased, what I observe is that the swinging motion dies out on the side of the group occupied by the shorter pendulums at the same time that it is being initiated on the other side. This causes the swinging motion to transfer itself, as it were, towards longer pendulums. I observed no "irregular jangling."

Now if this experimental resonator system does not show any "irregular jangling " as the incoming oscillations are varied in rate, there does not seem to be any reason for supposing that the ear, if it contained resonators, should hear an "irregular jangle of tones" when sound waves of steadily rising and falling pitch are incident on it. Therefore the fact that we hear a single tone steadily changing in pitch (and Prof. Scripture agrees that he also hears this), far from affording grounds for criticism of the resonance theory, actually lends it support, for that is precisely what an inspection of the behaviour of the pendulum apparatus would lead us to suppose that we ought to hear, if the ear contained a system of resonators.

In the second part of Prof. Scripture's letter he says that since the vowel sounds cannot be resolved into constituent tones (not even inharmonic ones), it follows that the ear which perceives vowels cannot resolve them into constituent vibrations either, and therefore cannot act according to the resonance theory.

Prof. Scripture's argument to my mind contains two flaws:

(I) He states that vowel sounds cannot be resolved into constituent tones.

(2) He states that since the ear recognises vowels it appreciates the presence of these unresolvable components and therefore it cannot contain resonators.

Let us admit for one moment for the sake of argument that such unresolvable components are present in vowel sounds. Now we know that the ear is able to recognise one vowel from another. But we are not justified in concluding that the ear appreciates these unresolvable components unless we can prove-

(a) that the unresolvable components differ in different vowel sounds;

(b) that in all other respects the vowel sounds are identical.

I believe I am right in stating that Prof. Scripture has not proved either of these.

But have we any real evidence that such unresolvable components exist? I hold that we have not. Even if Prof. Scripture has been able to obtain records of vowel sounds, that can be shown by experiment to be precise records of the variations of pressure in the air, and even if he has failed to resolve these records into their component tones (be they harmonic or inharmonic) he has, to my mind, merely proved that he has not spent sufficient time in testing all the innumerable possible combinations of amplitude, phase, and pitch.

Turning now to Prof. Scripture's sound pattern theory, may I point out to him that besides Waller's theory, that of Ewald will require his consideration. This is a matter of importance because Ewald did much interesting experimental work in his search for evidence in favour of his theory. In fact, if the resonance theory at any time failed to justify its existence, and gave forecasts which were disproved by experiment, it would be to Ewald's theory that I should look for a possible successor, unless indeed meanwhile Prof. Scripture elaborates a better one.

Finally, may I add that, although I regard the resonance theory of hearing as satisfactory, I am not one of those people referred to by Prof. Scripture, 